\title{
윤활이론을 이용한 유압부품설계 Application of Lubrication Theory to Hydraulic Components Design
}

\author{
박 태 조 \\ T. J. Park
}

\section{1. 서 론}

유압시스템의 설계에서 가장 주된 관심의 대상은 적절한 점도의 유체를 이용하여 효율적으로 에너지를 변환하는 것이다. 즉, 용적식 펌프를 사용하여 생성된 고압의 유체를 제어밸브와 배관계를 통해서 액추에이 터에 전달하고 이를 기계적 에너지로의 변환을 최대 화해야 된다. 이때, 펌프, 제어밸브 및 액추에이터 등 의 상대운동을 하는 모든 부품사이의 간극 (Clearance) 크기는 고압유체의 내부누설을 줄이기 위하여 가능하면 최소화하고 있다. 하지만 간극이 작 아질수록 유압유의 점성마찰로 인한 에너지손실은 증 대할 뿐만 아니라 이는 부차적으로 유온을 상승시키 는 등의 또 다른 악영향을 초래한다. 따라서, 유압부 품에서는 적절한 크기의 간극유지와 함께 점성마찰을 저감시키는 기술개발이 지속적으로 요구되고 있다. 특히, 유압기계가 일반기계의 경우와 다른 특징중의 하나는 작동유체인 유압유로 운동부를 윤활시키는 점 이다. 따라서, 고효율과 고내구성을 동시에 발휘하는 유압부품의 개발을 위해서는 상대운동부에서의 윤활 특성을 정확하게 고려한 설계가 요구된다.

본 해설에서는 유체윤활(Fluid film lubrication)에 관련된 이론을 간략하게 정리하고 이를 이용한 스푸 울 밸브(Spool valve)의 그루브(Groove) 설계방법과 함께 최근에 일반기계에서 적용되고 있는 Surface texturing이라는 최신의 마찰저감기술을 소개하였다.

\section{2. 유체윤활이론}

인류가 수 천년동안 발명한 각종 도구와 장치의 상 대운동부에서 발생하는 마찰을 줄이고 수명을 연장시 키기 위하여 사용한 가장 효율적인 방법은 점성유체 로 윤활하는 것이었다 ${ }^{1)}$. 하지만 이에 대한 이론적인 설명은 1886년에 O. Reynolds에 의해서 처음으로 제 시되었다 ${ }^{2)}$. 그는 B. Tower의 차축지지베어링에 대한 실험결과를 규명하고자 노력한 결과, 아주 얇은 유막 이 형성되는 것을 관찰하고 아래와 같은 가정을 유체
에 대한 운동방정식인 Naiver- Stokes 방정식에 적 용하고 이를 연속방정식을 결합시켰다. 이 결과, 오늘 날 레이놀즈 방정식(Reynolds equation)으로 알려져 있는 식(1)과 같은 새로운 형태의 미분방정식을 유도 하였다.

(1) 유막두께방향 $(z$ 방향 $)$ 으로의 압력변화는 없다.

(2) 유체의 체력(Body force)는 무시할 정도이다.

(3) 윤활면의 곡률은 유막두께에 비하여 매우 크다. (곡률의 영향을 무시한다.)

(4) 윤활면에서는 착벽( $\left.\mathrm{No}^{-} \mathrm{slip}\right)$ 조건을 만족한다.

(5) 윤활유는 뉴우튼 유체로 가정한다.

(6) 유체의 유동은 층류유동이다.

(7) 유체의 관성(Inertia)은 무시한다.

$$
\begin{aligned}
& \frac{\partial}{\partial x}\left(\frac{h^{3}}{\eta} \frac{\partial p}{\partial x}\right)+\frac{\partial}{\partial y}\left(\frac{h^{3}}{\eta} \frac{\partial p}{\partial y}\right) \\
& =6\left[\left(u_{a}+u_{b}\right) \frac{\partial h}{\partial x}+\left(v_{a}+v_{b}\right) \frac{\partial h}{\partial y}\right. \\
& \quad+h \frac{\partial}{\partial x}\left(u_{a}+u_{b}\right)+h \frac{\partial}{\partial y}\left(v_{a}+v_{b}\right) \\
& \left.\quad+2\left(w_{a}-w_{b}\right)\right]
\end{aligned}
$$

여기서, 하첨자 $a$ 는 윗면, $b$ 는 아랫면을 의미한다. 식(1)에서 알 수 있는 것과 같이 유막내에서 발생 하는 압력(Hydrodynamic pressure) $p$ 는 윤활면의 형 상, 운전속도 및 오일의 점도 $\eta$ 에 의해서 거의 결정 된다. 인위적인 조작없이 유막내에서 $(+)$ 압력이 발생 하기 위해서는 식(1)의 우변항이 음(-)의 값을 가져 야 하며, 이러한 경우의 베어링을 동압베어링 (Hydrodynamic bearing)이라고 부른다. 이때, 압력발 생에 기여하는 식(1) 우변항의 각항에 대한 물리적 의미는 다음과 같으며, 순서대로 이를 그림으로 나타 내면 그림1과 같다.

(1) 쐐기 작용 (Wedge action)

(2) 늘이기 작용 (Stretch action)

(3) 짜내기 작용 (Squeeze action) 


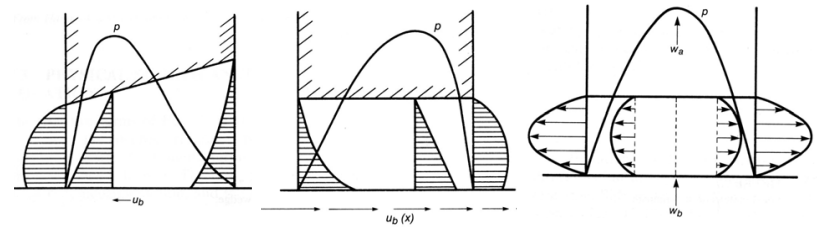

그림 1 동압베어링에서의 압력발생 기구

즉, 윤활상태에서는 유체의 점성작용으로 유막내에 서 발생하는 압력이 하중과 평형을 유지하므로 상대 운동면은 서로 접촉하지 않는다. 따라서, 운동면에 작 용하는 저항력은 유체의 전단에 기인한 점성마찰력 뿐이기에 건마찰(Dry friction)이나 경계윤활 (Boundary lubrication) 상태인 경우에 비하여 마찰계

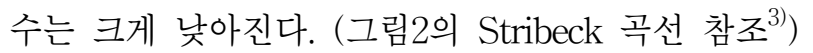

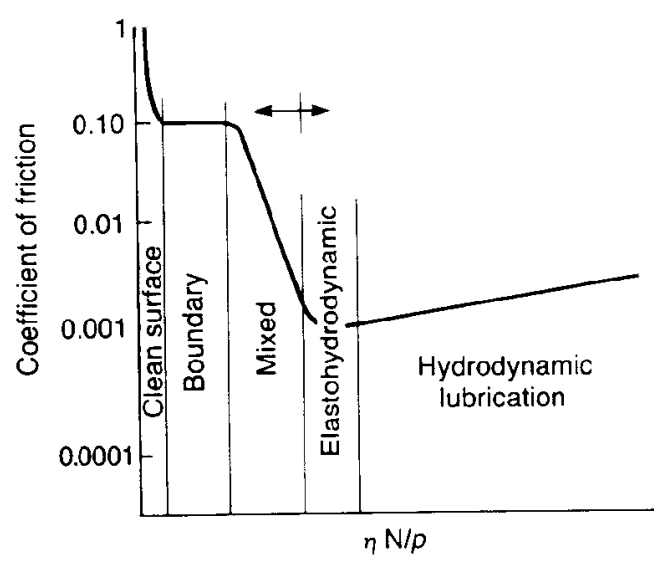

그림 2 Stribeck curve
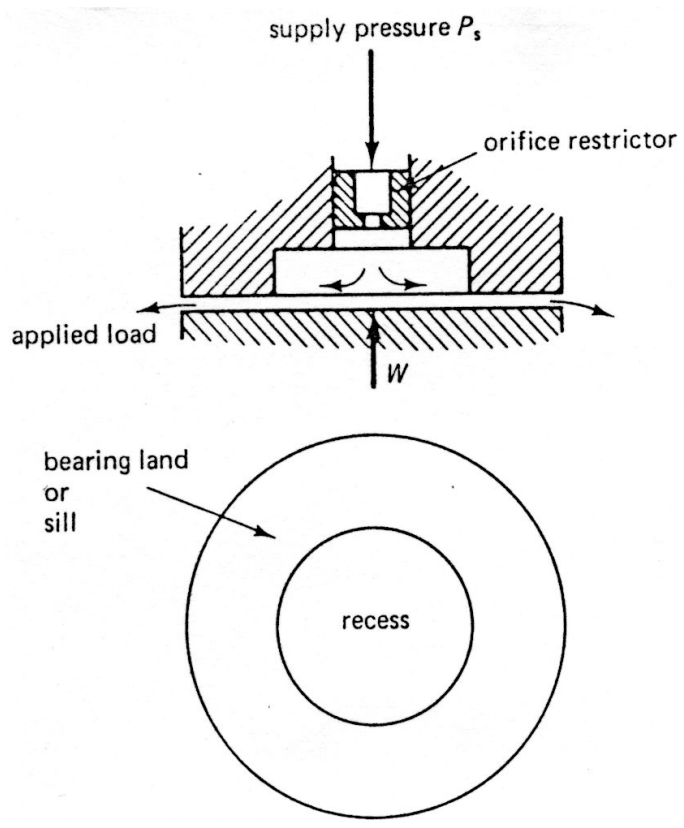

그림 3 정압베어링의 하중지지
만일 식(1) 우변항의 값이 아주 작거나 0인 경우에 는 그림3에 나타낸 것과 같이 펌프(Pump)나 압축기 (Compressor)로 가압한 유체를 윤활면 사이에 공급 하여 하중이 작용하는 윤활면을 서로 분리시킨다. 이 러한 형태의 베어링을 정압베어링 (Hydrostatic bearing)이라고 부른다. 참고로 하이브리드 베어링 ((Hybrid bearing)은 동압베어링과 정압베어링의 기 능을 동시에 사용하는 경우를 말하며, 사판식 피스 톤 펌프·모터에서 피스톤-슈가 이에 해당된다. 유 체윤활상태에서는 표면거칠기에 비하여 충분한 크 기의 유막으로 윤활면이 분리되기 때문에 적절하게 설계/제작되고 적합한 윤활유를 사용하여 관리하면 이론적인 수명은 무한하다. 참고로 탄성유체윤활 (Elastohydrodynamic lubrication) 영역(그림2)은 발 생압력에 따른 윤활면의 탄성변형과 윤활유의 점도변 화가 동시에 나타나는 경우로 유압부품에서는 기어 펌프·모터의 잇면사이, 베인 펌프·모터의 베인과 캠 링 사이 등에서 발생한다. 지금은 베어링 뿐만 아니 라 유압부품의 설계와 성능해석에도 식(1)이 널리 사 용되고 있다.

\section{3. 스푸울 밸브의 그루브 설계}

\section{1 그루브의 위치설계}

\subsection{1 개요}

유압장치에서는 유압유의 제어를 위하여 스푸울 밸브를 많이 사용하고 있다. 이때, 스푸울과 슬리브 (Sleeve) 사이의 아주 작은 간극을 흐르는 유압유의 박막유동에 의해서 스푸울 주위로 비대칭적인 압력분 포가 형성될 수 있으며, 이로 인하여 스푸울의 반경 방향으로 작용하는 힘인 측력(Lateral force)이 발생 한다. 만일, 측력의 작용으로 편심된 스푸울이 슬리브 면 쪽으로 더욱 편심되게 되면 마찰력이 증가할 뿐만 아니라 경우에 따라서는 스푸울과 슬리브 내벽에 과 도한 마멸을 유발시키게 된다. 유체고착(Hydraulic locking) 현상이라고 유압공학분야에서 아주 잘 알려 져 있는 문제이다 ${ }^{4-22)}$. 실제에서 이 문제의 해결에 많 이 적용되는 방법은 그림4에 나타낸 것과 같이 스푸 울 둘레에 여러개의 그루브를 두는 것이다. 본 장에 서는 앞에서 소개한 레이놀즈 방정식을 사용하여 측 력이 최소인 그루브 위치의 설계방법과 수치해석에 의한 그루브 단면의 형상과 크기에 따른 그루브내에 서의 유동특성을 소개하고자 한다. 결과는 스푸울 밸 브 뿐만 아니라 왕복동인 유압 피스톤 펌프·모터와 유압 실린더에도 그대로 적용할 수 있다. 


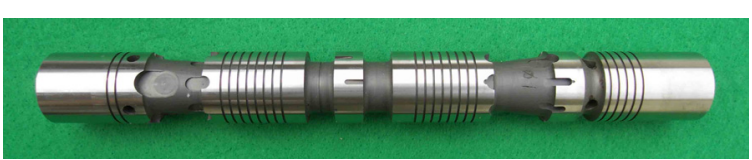

그림 4 유압 스푸울 밸브
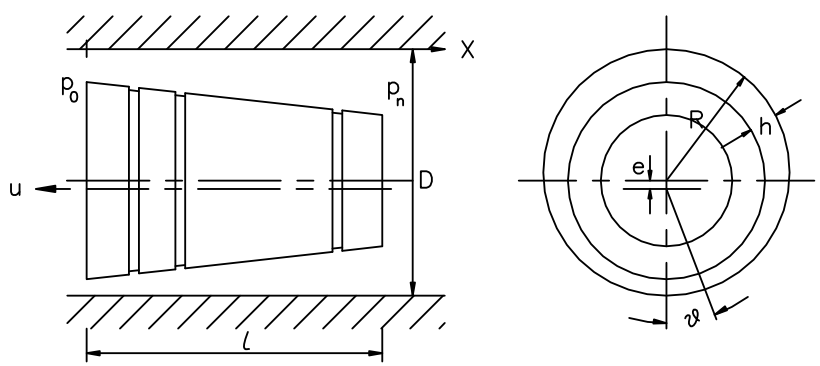

그림 5 그루브가 있는 스푸울 모델 및 좌표계

\subsection{2 지배방정식 및 무차원화}

유막내에서 유체압력은 지배하는 식(1)의 레이놀즈 방정식을 스푸울과 슬리브 사이인 경우에는 다음 형 태로 나타낼 수 있다.

$$
\frac{\partial}{\partial x}\left(\frac{h^{3}}{\eta} \frac{\partial p}{\partial x}\right)+\frac{1}{R^{2}} \frac{\partial}{\partial \theta}\left(\frac{h^{3}}{\eta} \frac{\partial p}{\partial \theta}\right)=6 u \frac{\partial h}{\partial x}
$$

그림5와 같이 다수의 그루브가 있는 스푸울이 슬리 브 축에 대하여 $e$ 만큼 편심된 경우, 유막두께는 다음 식으로 나타내어진다.

$$
\begin{aligned}
h & =h_{o}+\frac{x}{l}\left(h_{n}-h_{o}\right) \\
& =c_{o}-e \cos \theta+\frac{x}{l}\left(c_{n}-c_{o}\right)
\end{aligned}
$$

여기서, $h_{o}=c_{o}-e \cos \theta, h_{n}=c_{n}-e \cos \theta$ 로 각각 $\mathrm{x}=0, \mathrm{x}=l$ 에서의 유막두께이다.

유압유로 주로 사용되는 석유계 오일(Mineral oil) 의 점도는 압력에 따라서 다음과 같이 변화한다.

$$
\eta=\eta_{o} e^{\alpha p}
$$

여기서, $\eta_{o}$ 는 대기압 상태에서의 점도, $\alpha$ 는 오일의 압력-점도 지수(Pressure-viscosity coefficient)로 대 략 $15 \sim 45 \times 10^{-9} \mathrm{~Pa}^{-1}$ 범위에 있다.

스푸울 양단부에 작용하는 압력은 다음과 같다.

$$
x=0, \quad p=p_{o} \quad: \quad x=l, \quad p=p_{n}
$$

원주방향으로의 비대칭적인 압력분포로 인하여 스 푸울에 작용하는 측력 $w$ 와 간극을 통하는 유압유의 누설유량 $q$ 는 각각 다음 식에서 구할 수 있다.

$$
\begin{aligned}
& w=R \int_{o}^{l} \int_{o}^{2 \pi} p \cos \theta d \theta d x \\
& q=R \int_{o}^{2 \pi}\left(\frac{u h}{2}-\frac{h^{3}}{12 \eta} \frac{\partial p}{\partial x}\right) d \theta
\end{aligned}
$$

해석을 간단히 하기 위하여 다음의 식(8)과 같은 무차원변수와 식(9)의 관계식을 도입한다.

$$
\begin{aligned}
& X=x / l, H=h / c_{o}, k_{n}=c_{n} / c_{o}, \epsilon=e / c_{o}, \\
& L=l / R, P=p / p_{d}, \bar{\eta}=\eta / \eta_{o}, G=\alpha p_{d}, \\
& \lambda=6 \eta_{o} u l / p_{d} c_{o}^{2}, \quad W=w / \pi R^{2} p_{d}, \\
& Q=6 \eta_{o} q l / \pi R p_{d} c_{o}^{3}
\end{aligned}
$$

$$
\bar{P}=\frac{1}{G}\left(1-e^{-G P}\right)
$$

여기서, $\mathrm{G}$ 는 압력-점도 변수 (Pressure-viscosity parameter)로 $G \rightarrow 0$ 이면 $\bar{P} \rightarrow P$ 이다.

따라서, 식(2) (3), 식(5) 식(7)의 무차원형태를 순서대로 나타내면 다음과 같다.

$$
\begin{aligned}
& \frac{\partial}{\partial X}\left(H^{3} \frac{\partial \bar{P}}{\partial X}\right)+L^{2} \frac{\partial}{\partial \theta}\left(H^{3} \frac{\partial \bar{P}}{\partial \theta}\right)=\lambda \frac{\partial H}{\partial X} \\
& H=H_{o}+\left(H_{n}-H_{o}\right) X=1-\epsilon \cos \theta+\left(k_{n}-1\right) X \\
& X=0, \bar{P}=\overline{P_{o}} \quad: \quad X=1, \bar{P}=\overline{P_{n}} \\
& \frac{W}{L}=\frac{2}{\pi} \int_{o}^{1} \int_{o}^{\pi} P \cos \theta d \theta d X \\
& Q=\frac{1}{\pi} \int_{o}^{\pi}\left(\lambda H-H^{3} \frac{d \bar{P}}{d X}\right) d \theta
\end{aligned}
$$

\subsection{3 그루브 위치설계}

스푸울의 길이가 반경에 비하여 짧거나 $(L<1)$ 편심률 $(\epsilon)$ 이 작은 경우, 식(10)은 다음 식과 같이 1 차원 형태로 나타낼 수 있다. 특히, 그루브의 수가 다수인 경우에는 이러한 근사는 타당성을 가지게 된다.

$$
\frac{\partial}{\partial X}\left(H^{3} \frac{\partial \bar{P}}{\partial X}\right)=\lambda \frac{\partial H}{\partial X}
$$

그림6은 이론해석을 위한 그림으로 $\mathrm{s}$ 개의 그루브 가 길이방향으로 $\mathrm{X}=\mathrm{X}_{1}, \mathrm{X}_{2}, \cdots, \mathrm{X}_{\mathrm{s}}$ 에 위치해 있다. 

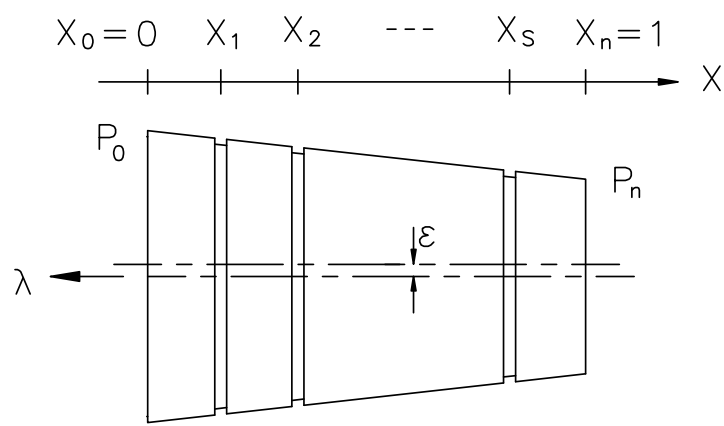

그림 6 다수의 그루브가 있는 스푸울 모델

만일, 그루브의 폭과 깊이가 유막두께에 비해서 충분 히 클 경우에는 각 그루브내에서의 원주방향 압력은 일정하다. 따라서, 그루브가 $\mathrm{s}$ 개인 스푸울은 $(\mathrm{s}+1)$ 개 의 길이가 짧은 스푸울(sub-spool)이 연결되어 있는 문제로 생각할 수 있으며, 이때, 각각의 짧은 스푸울 양단부에는 각 그루브 압력 $P_{1}, P_{2}, \cdots, P_{s}$ 이 작용한 다. 따라서, 식(9)의 관계식을 이용하여 변환한 그루 브 압력을 경계조건으로 적용하면 식(15)의 해인 $\bar{P}$ 는 식(16)과 같이 구해진다 ${ }^{13-14,16,22)}$.

$$
\begin{aligned}
& \bar{P}=\overline{P_{o}}-\left(\overline{P_{o}}-\overline{P_{1}}\right) \frac{H_{1}^{2}}{H_{1}^{2}-H_{o}^{2}}\left(1-\frac{H_{o}^{2}}{H^{2}}\right) \quad 0 \leq X \leq X_{1} \\
& +\frac{\lambda}{k_{n}-1}\left(-\frac{1}{H}+\frac{H_{o} H_{1}}{\left(H_{o}+H_{1}\right) H^{2}}+\frac{1}{H_{o}+H_{1}}\right) \\
& \cdot . \\
& =\overline{P_{s}}-\left(\overline{P_{s}}-\overline{P_{n}}\right) \frac{H_{n}^{2}}{H_{n}^{2}-H_{s}^{2}}\left(1-\frac{H_{s}^{2}}{H^{2}}\right) \quad X_{s} \leq X \leq 1 \\
& +\frac{\lambda}{k_{n}-1}\left(-\frac{1}{H}+\frac{H_{s} H_{n}}{\left(H_{s}+H_{n}\right) H^{2}}+\frac{1}{H_{s}+H_{n}}\right)
\end{aligned}
$$

한편, 각 그루브를 통과하는 누설량은 동일하므로 식(14)에 식(16)의 결과를 사용하여 정리하면 각 그루 브에서의 $\overline{P_{1}}, \overline{P_{2}}, \cdots, \overline{P_{s}}$ 를 구할 수 있다.

$$
\begin{aligned}
& Q=\frac{\overline{P_{o}}-\overline{P_{1}}}{X_{1}} S_{o 1}+\lambda T_{o 1} \quad 0 \leq X \leq X_{1} \\
& =\frac{\overline{P_{a}}-\overline{P_{b}}}{X_{b}-X_{a}} S_{a b}+\lambda T_{a b} \quad X_{a} \leq X \leq X_{b} \\
& =\frac{\overline{P_{s}}-\overline{P_{n}}}{1-X_{s}} S_{s n}+\lambda T_{s n} \quad X_{s} \leq X \leq 1
\end{aligned}
$$

여기서, $S_{a b}, T_{a b}$ 은 각각 다음과 같이 나타내어진 다.

$$
\begin{aligned}
& S_{a b}=\frac{2}{\pi} \int_{o}^{\pi} \frac{H_{a}^{2} H_{b}^{2}}{H_{a}+H_{b}} d \theta \\
& =\frac{2 k_{a}^{2} k_{b}^{2}}{\sqrt{\left(k_{a}+k_{b}\right)^{2}-4 \epsilon^{2}}}+\frac{\left(k_{a}+k_{b}\right)\left(k_{a}^{2}-6 k_{a} k_{b}+k_{b}^{2}\right)}{8} \\
& \cdot\left\{\frac{k_{a}+k_{b}}{\sqrt{\left(k_{a}+k_{b}\right)^{2}-4 \epsilon^{2}}}-1\right\}+\frac{3}{4} \epsilon^{2}\left(k_{a}+k_{b}\right) \\
& T_{a b}=\frac{2}{\pi} \int_{o}^{\pi} \frac{H_{a} H_{b}}{H_{a}+H_{b}} d \theta \\
& =\frac{1}{2}\left\{k_{a}+k_{b}-\frac{\left(k_{b}-k_{a}\right)^{2}}{\sqrt{\left(k_{a}+k_{b}\right)^{2}-4 \varepsilon^{2}}}\right\}
\end{aligned}
$$

여기서, $\mathrm{a}=0,1,2, \cdots, \mathrm{s}$ 및 $\mathrm{b}=\mathrm{a}+1$ (단, $\mathrm{a}=\mathrm{s}$ 이면 $\mathrm{b}=\mathrm{n})$ 이고, $k_{a}=1+\left(k_{n}-1\right) X_{a}$ 이다.

하나의 예로서 $\mathrm{X}=\mathrm{X}_{1}$ 에 1 개의 그루브가 있는 경우, $\overline{P_{1}}$ 은 다음 식으로 표현된다.

$$
\overline{P_{1}}=\frac{\left(1-X_{1}\right) S_{o 1} \overline{P_{o}}+X_{1} S_{1 n} \overline{P_{n}}+\lambda X_{1}\left(1-X_{1}\right)\left(T_{o 1}-T_{1 n}\right)}{X_{1} S_{1 n}+\left(1-X_{1}\right) S_{o 1}}
$$

따라서, 유막내에서의 무차원압력 $P$ 는 다음 식에 서 구할 수 있다.

$$
P=-\frac{1}{G} \ln (1-G \bar{P})
$$

스푸울에 작용하는 무차원 측력은 식(13)을 수치적 분하면 구할 수 있으며, 점도가 일정한 경우 $(\mathrm{G}=0)$ 에 는 다음 식과 같이 해석적으로 나타낼 수 있다.

$$
\begin{gathered}
\frac{W^{(s)}}{L}=\frac{1}{2 \epsilon}\left[\left(k_{n}-1\right) \sum_{i=1}^{s+1}\left(P_{i-1}-P_{i}\right)\left(X_{i}-X_{i-1}\right)^{2}\right. \\
\cdot\left\{1-\frac{k_{i-1}++k_{i}}{\sqrt{\left(k_{i-1}+k_{i}\right)^{2}-4 \epsilon^{2}}}\right\}+\frac{4 \lambda}{k_{n}-1}\left\{\frac{\sqrt{1-\epsilon^{2}}-\sqrt{k_{n}^{2}-\epsilon^{2}}}{k_{n}-1}\right. \\
\left.\left.+\sum_{i=1}^{s+1} \frac{\left(X_{i}-X_{i-1}\right)\left(k_{i-1}+k_{i}\right)}{\sqrt{\left(k_{i-1}+k_{i}\right)^{2}-4 \epsilon^{2}}}\right\}\right]
\end{gathered}
$$

이상에서 제시한 압력분포, 스푸울에 작용하는 측력 및 누설유량에 대한 표현식으로부터 유체고착을 최소 
화할 수 있는 그루브의 위치를 쉽게 구할 수 있다.

\subsection{4 결과 및 고찰}

스푸울 밸브에서 유체고착이 발생하기 쉬운 조건 은 테이퍼진 스푸울의 대단부에 고압 $\left(P_{o}=1\right)$ 이 작용 하는 상태에서 스푸울이 고압측으로 운동 $(\lambda>0)$ 하는 경우로 그림7에는 이에 대한 압력분포를 나타내었다. 이 결과, 편심방향인 $\theta=0^{\circ}$ 에서의 압력이 $\theta=180^{\circ}$ 에서 보다 한층 낮으므로 유체압력은 편심된 스푸울을 슬 리브의 내벽쪽으로 보내려는 고착력(Locking force) 로 작용한다. 이러한 경우에 그루브를 설치(그림에서 는 $\left.X_{1}=0.32\right)$ 하면 원주방향으로의 압력차이가 크게 감소하기 때문에 유체고착이 발생할 가능성을 줄일 수 있다.

그루브가 1 개인 경우, 이의 위치가 길이방향으로 변할 때의 측력과 누설유량을 그루브가 없는 경우의 결과에 대한 비를 그림8에 나타내었다. 그루브의 위 치에 따라서 측력의 크기는 아주 크게 달라진다. 특 히, 측력이 최소인 그루브 위치가 존재하며, 간극을 통하는 누설량은 미세하지만 이 부근에서 최대로 되 었다.

그림9는 그루브의 수에 따른 측력과 누설량의 변화 를 나타낸 결과로 그루브의 위치는 측력이 최소인 경 우이다. 그루브가 많아질수록 측력은 작아지지만 이 의 감소효과는 상대적으로 줄어들며, 누설량은 이와 반대의 경향을 나타내었다.

Table 1에는 Mannam ${ }^{7)}$ 이 실험으로 구한 측력의 감소비와 본 저자가 이론적으로 구한 결과를 비교하 여 나타낸 것으로 상당히 잘 일치하였다 ${ }^{13)}$. 여기서 사 용한 조건은 $\lambda=0, \epsilon=1, k_{n}=5.2$ 이다.

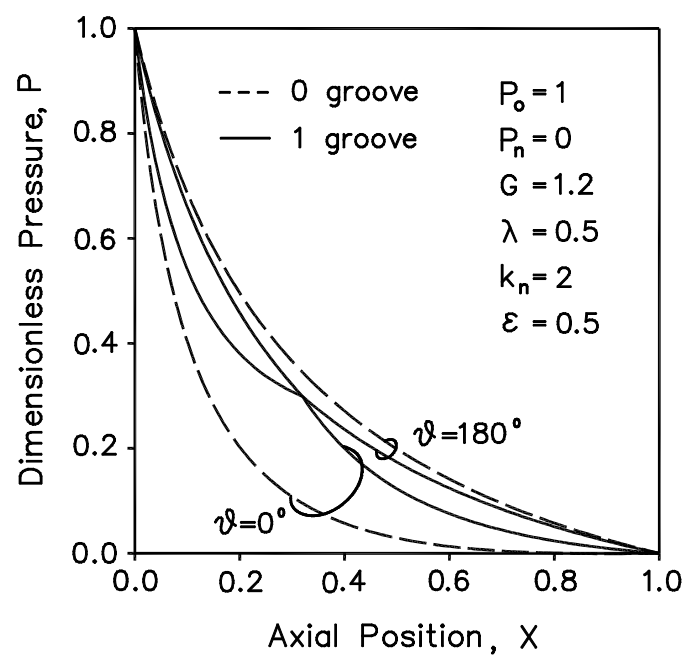

그림 7 간극에서의 압력분포

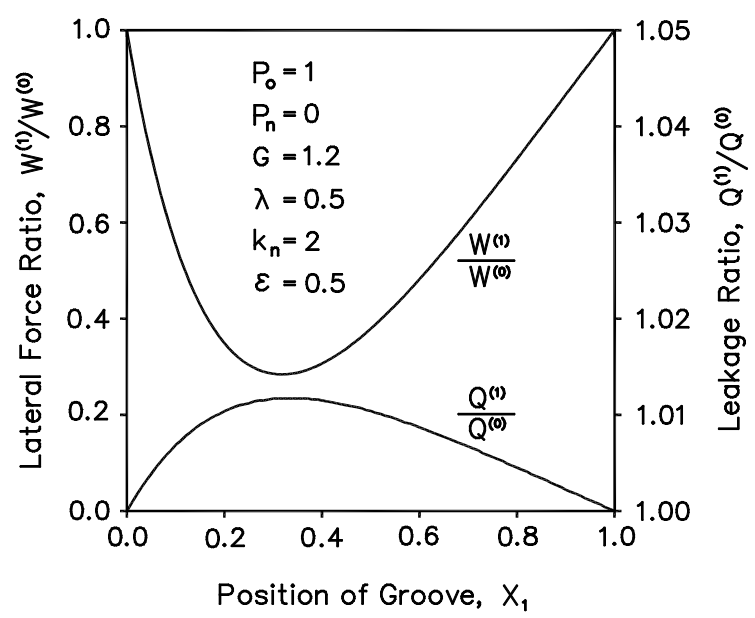

그림 8 그루브 위치와 측력과 누설유량과의 관계

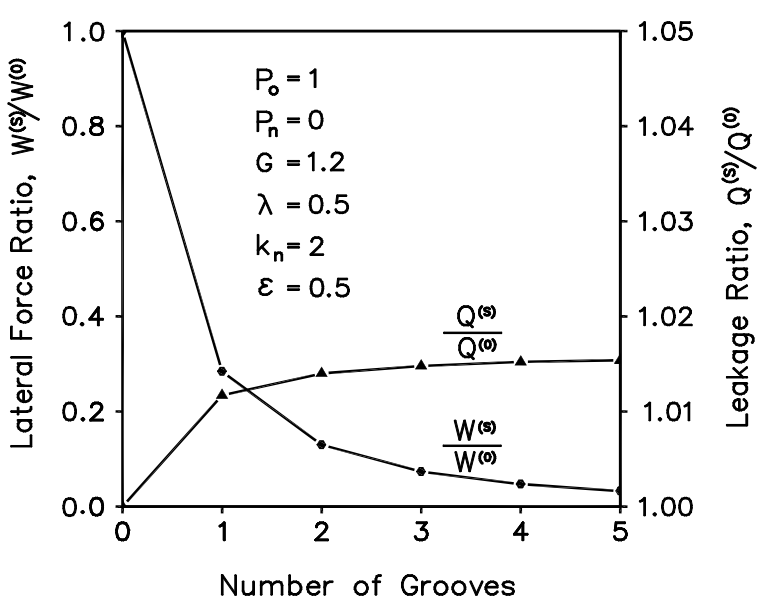

그림 9 그루브 수와 측력과 누설유량과의 관계

Table 1 그루브의 최적위치

\begin{tabular}{|c|c|c|c|c|}
\hline \multirow{2}{*}{$\begin{array}{l}\text { 그루 } \\
\text { 브수 }\end{array}$} & \multicolumn{2}{|c|}{$\mathrm{W}^{(\mathrm{S})} / \mathrm{W}^{(0)}$} & \multirow[b]{2}{*}{ 최적위치, $\mathrm{X}_{\mathrm{i}}$} & \multirow{2}{*}{$\begin{array}{l}\text { 실험 결 과 } \\
\mathrm{W}^{(\mathrm{S})} / \mathrm{W}^{(0)}\end{array}$} \\
\hline & 등간격 & $\begin{array}{l}\text { 최적 } \\
\text { 위치 }\end{array}$ & & \\
\hline 1 & 59.2 & 36.1 & 0.21 & 58 \\
\hline 2 & 39.1 & 17.9 & $0.11,0.34$ & \\
\hline 3 & 27.7 & 10.6 & $0.07,0.20,0.43$ & 24 \\
\hline 4 & 20.7 & 7.0 & $0.05,0.13,0.27,0.51$ & \\
\hline 5 & 16.0 & 4.9 & $\begin{array}{l}0.04,0.10,0.19,0.33 \text {, } \\
0.56\end{array}$ & \\
\hline
\end{tabular}

3.2 그루브 단면형상의 영향

\subsection{1 개요}

그루브의 위치는 앞절의 레이놀즈 방정식에서 구 한 이론식을 사용하여 설계할 수 있지만 이의 폭과 깊이는 간극의 크기에 비하여 아주 크므로 그루브내 의 유동을 박막유동으로 가정할 수가 없다. 따라서, 그루브 크기와 단면형상 등에 따른 그루브내에서의 
유동특성은 비압축성, 정상상태, 층류유동에 대한 Navier-Stokes 방정식과 연속방정식을 $\mathrm{CFD}$ (Computational fluid dynamics) 해석방법을 사용하 여 구하였다 ${ }^{23)}$. 제시한 결과는 정지상태인 스푸울의 양단에 차압이 작용하는 경우로 한정하였다. Fig.10은 그루브 단면형상이 다른 경우의 유선의 분포를 비교 한 결과로 사각형과 삼각형에서는 모서리부에서 $\mathrm{Eddy}$ 가 발생하지만 U형인 경우는 발생하지 않았다. 즉, 단면이 유선형에 가까울수록 Eddy의 발생이 억제 될 것으로 예상된다. 그루브의 크기가 다르더라도 단 면형상이 동일하면 유선의 분포는 동일함을 그림11에 서 알 수 있다.
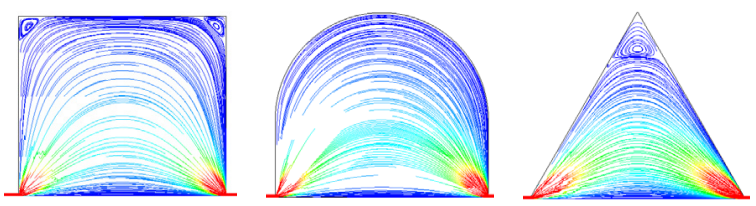

그림 10. 그루브 단면형상과 유선분포.

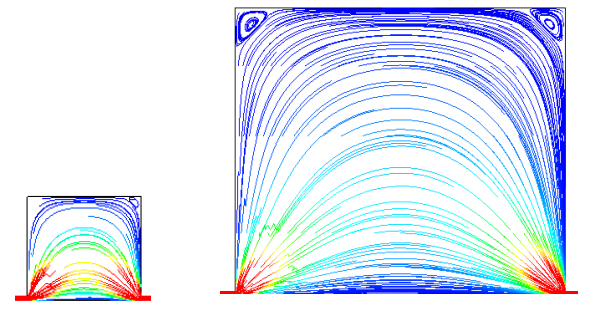

그림 11 그루브 단면 크기와 유선분포.
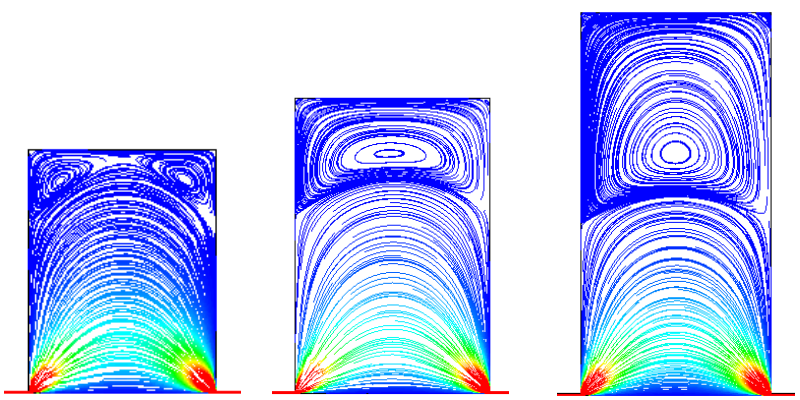

그림 12 그루브 깊이와 유선분포

그림12는 그루브 깊이가 다른 경우의 결과로 깊어 질수록 그림10에서 관찰된 모서리부 Eddy가 점차 성 장하여 와류(Vortex)로 발달하고 더욱 깊어지면 와류 의 수가 추가될 것이다 ${ }^{24-25)}$. 이러한 와류의 생성은 그 루브내의 압력분포에는 거의 영향을 미치지 않지만 유온상승이나 운전조건에 따라서는 캐비테이션을 발 생시키는 원인으로 작용할 것으로 예상된다. 하지만 이물질이나 마모입자를 그루브내에 가두는 역할을 하 여 랜드부나 슬리브 내면에서의 연삭마모발생을 줄이
는데 효과적일 것이다. 3.1절에서 고찰한 바와 같이 그루브는 누설량을 증가시키지만 어느 한도 이상에서 는 단면형상과 깊이에 따른 영향이 상대적으로 줄어 들고 있다(그림13).

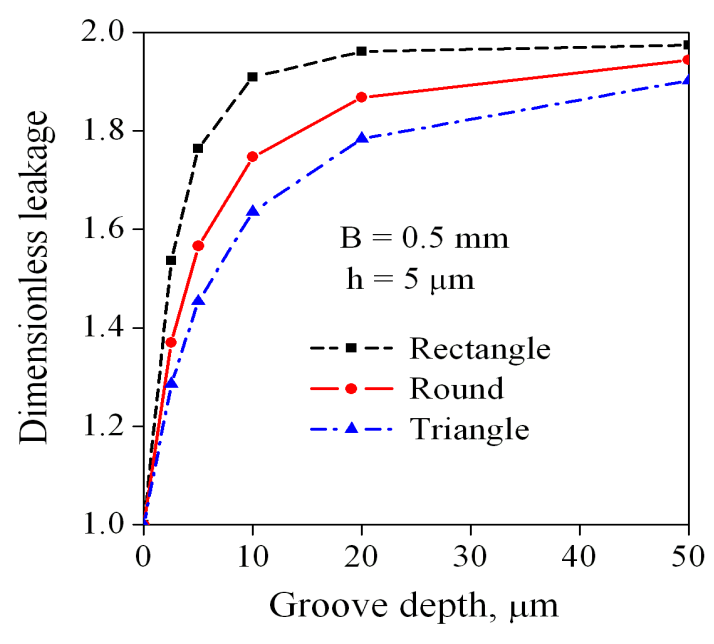

그림 13. 그루브 깊이가 누설량에 미치는 영향

그루브의 깊이를 고정한 상태에 이의 폭을 변화시 킨 경우에 대한 유선분포와 누설량의 변화를 그림14 와 그림15에 각각 나타내었다. 동일한 그루브 깊이에 서도 깊이/폭의 비가 증가하면 그림 12 에서와 동일하 게 큰 와류가 발생하였다. 한편, 그루브의 폭이 커질 수록 누설량은 급격하게 증가하였다.

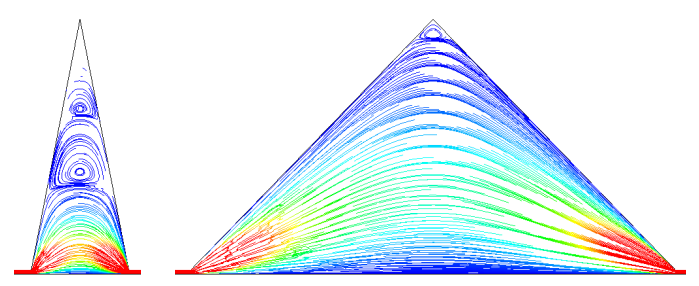

그림 14 그루브 폭과 유선분포

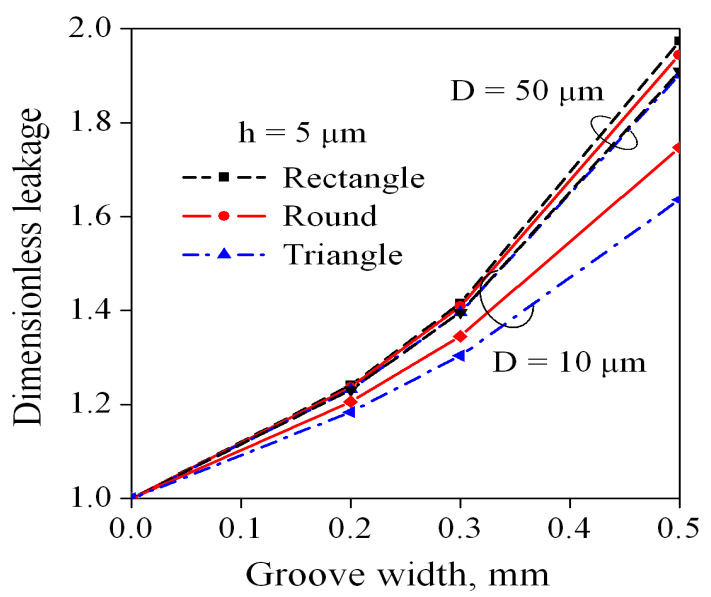

그림 15 그루브 폭이 누설량에 미치는 영향 


\section{4. 윤활면의 마찰저감 신기술 소개}

\section{1 개요}

지금까지 기계부품면에서 발생하는 마찰을 줄이는 가장 효율적인 방법은 정밀가공한 부품을 사용하고 운전시에 유체윤활상태를 유지하는 것이었다. 거의 경계윤활(Boundary lubrication) 상태로 운전되는 기 계부품면에 미세한 크기의 포켓(Pocket)이나 딤플 (Dimple) 등을 가공하면 상당한 정도의 마찰감소와 함께 수명과 내구성을 크게 향상시킬 수 있다는 실험 결과가 지난 10 여년 사이에 제시되었다. ${ }^{26-28)}$ Surface texturing이라고 불리어지는 새로운 표면가공에 의한 딤플 등이 윤활유 저장조(Reservoir)와 마멸입자를 포집하는 필터(Filter)로서의 기능뿐만 아니라 압력을 발생시키는 소형의 동압베어링으로도 작용할 수 있다 는 결과는 최근에 제시되었다. 그림16은 다양한 크기 와 형태로 Surface texturing한 미끄럼 베어링 표면을 확대한 사진이다. 본 장에서는 유압부품에 Surface texturing 방법은 적용한 경우의 윤활특성을 소개하 고자 한다 ${ }^{29-33)}$.

\section{2 해석모델}

그림 17 은 유압부품에서와 같이 양단에 차압이 작 용하고 있는 다수의 원형 딤플이 있는 스러스트 베어 링 모델이다. 여기서, 딤플이 있는 위치에서는 딤플이 없는 부분보다 유막두께가 한층 크고 형상도 급격하 게 변화하므로 Navier-Stokes 방정식과 연속방정식 을 $\mathrm{CFD}$ 해석방법으로 해석하였다.

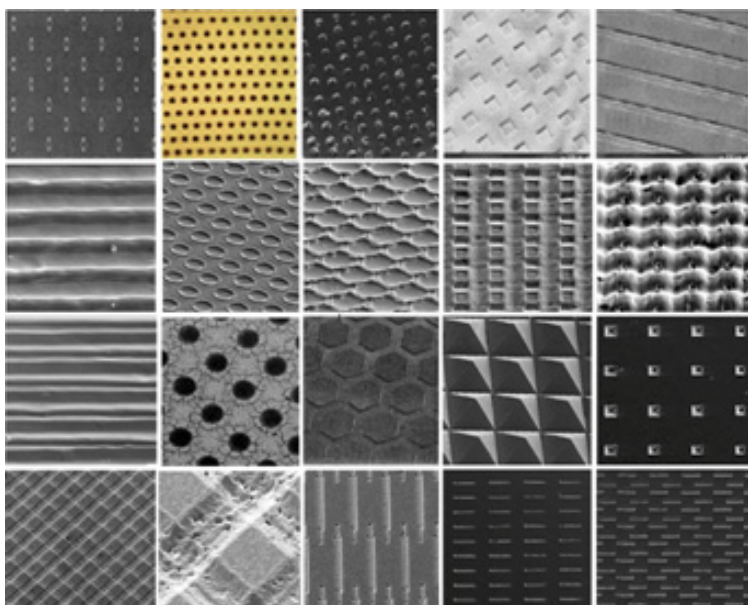

그림 16 Surface texturing한 미끄럼 베어링면

\section{3 결과 및 고찰}

그림 18 은 $x-z$ 단면에서의 유선의 분포를 나타낸
그림으로 각 딤플내에는 하나의 큰 와류가 형성되었 다. 딤플내에서의 와류는 유압시스템 내부에서 발생 한 마멸입자나 외부에서 침투한 경질입자를 가두는 일종의 미세필터(micro-Filter) 역할을 할 것으로 예 상된다.

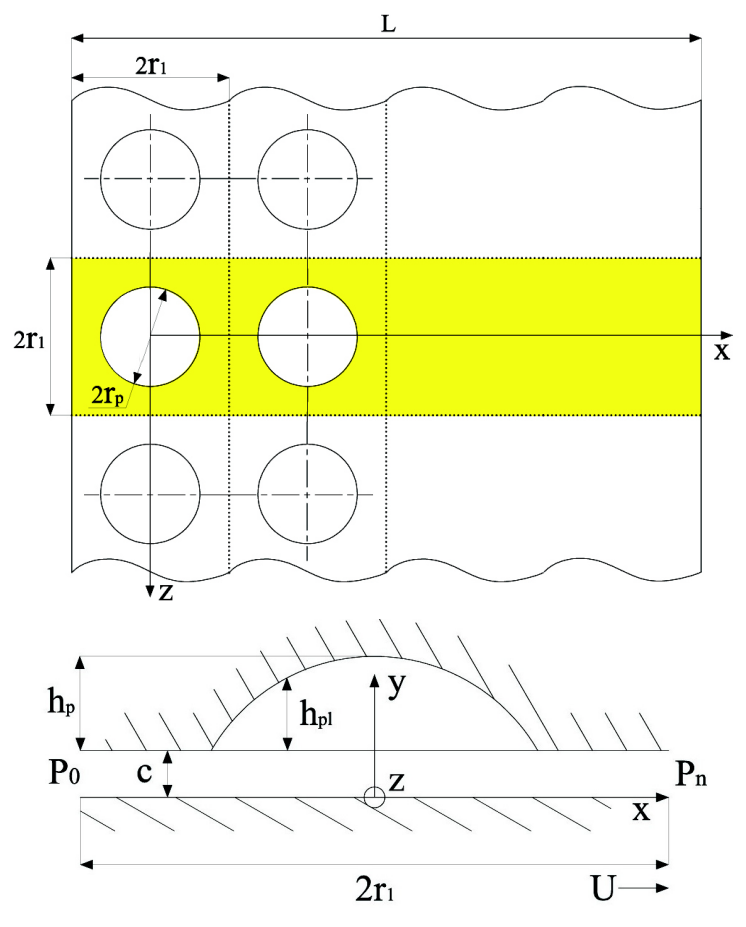

그림 17 해석 모델

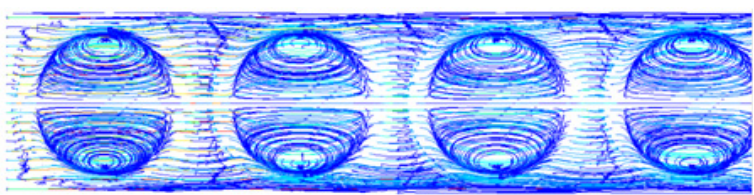

그림 18 유선분포

그림19는 입구부(왼쪽)에서부터 순차적으로 딤플 이 추가되는 경우의 압력분포를 나타낸 것으로 왼 쪽의 숫자는 왼쪽에서부터 배치된 딤플의 전체수를 의미한다. 그림 20 는 딤플이 없는 경우, 최대압력이 발생하는 경우(6개) 및 전길이에 걸쳐서 가공된 경 우(10개)에 대한 $z=0$ 에서의 압력분포를 비교한 결 과이다. 윤활면이 평행하므로 딤플이 없는 경우에는 윤활작용으로 동압이 발생하지 않기 때문에 압력분 포는 직선적으로 변화한다. 하지만 딤플이 있는 경 우에는 추가적으로 상당한 정도의 동압이 발생하고 있다. 따라서 딤플을 적절하게 설계하면 윤활면이 평행한 경우에도 상당한 정도의 하중을 추가로 지 지할 수 있으므로 유압부품의 윤활성능을 향상시킬 수 있을 것으로 예상된다. 


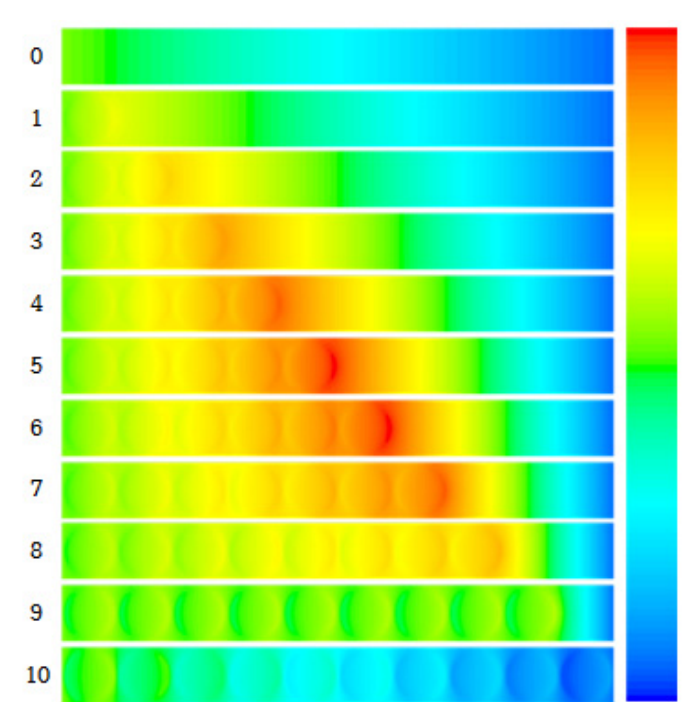

그림 19 딤플의 수에 따른 압력분포

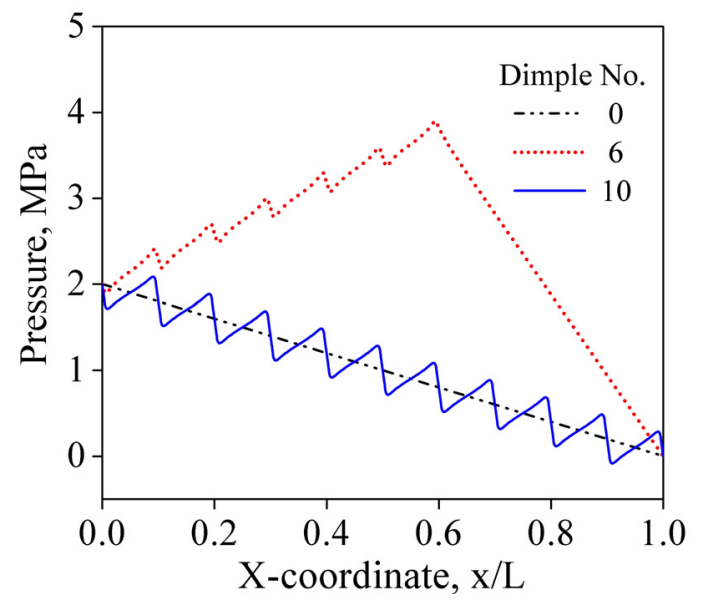

그림 20 딤플의 수에 따른 압력분포

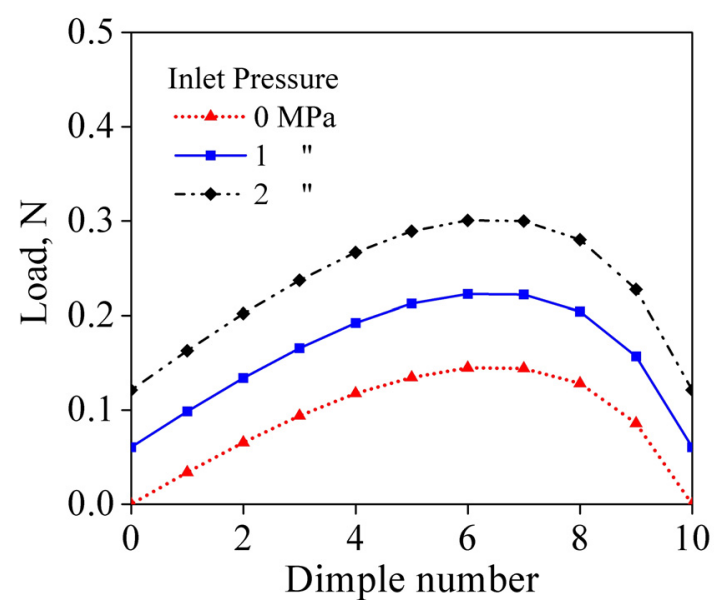

그림 21 딤플의 수에 따른 지지하중의 변화

그림21 그림23에는 입구부 압력과 딤플수에 따른 베어링의 지지하중, 윤활면에 작용하는 마찰력 및 간 극을 통하는 누설유량(이론급유량)을 순서대로 나타
내었다. 여기서, 마찰력과 누설유량은 딤플이 없는 경 우의 값으로 무차원화였다. 앞에서 고찰한 바와 같이 지지하중은 딤플이 추가될수록 점차 증가하여 6개인 경우에 최대치에 도달한 다음 급격하게 감소하였다. 딤플이 많아지고 입구에 고압이 작용할수록 베어링에 작용하는 마찰력은 크게 감소하는 반면에 누설유량은 증가하였다.

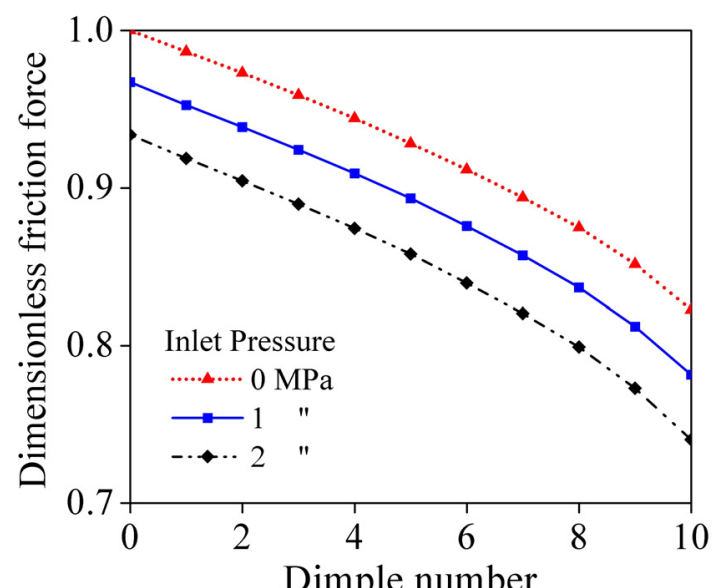

그림 22 딤플의 수에 따른 마찰력의 변화

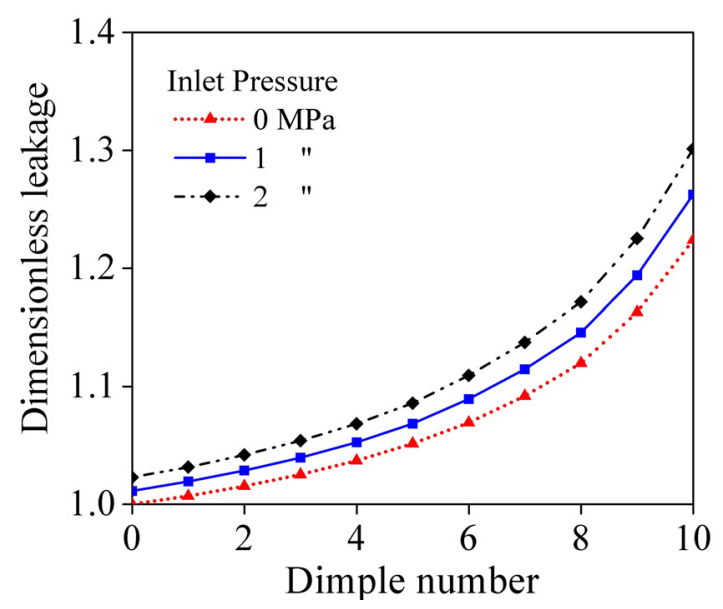

그림 23 딤플의 수에 따른 누설유량의 변화

이상에서 고찰한 바와 같이 유압부품면에 적절한 형태의 Surface texturing 처리를 하면 점성마찰력을 크게 감소시킬 뿐만 아니라 하중지지능력도 향상시킬 수 있기 때문에 고효율과 고내구성을 동시에 달성할 수 있다.

\section{4. 결 론}

본 해설에서는 단순한 형태의 유체윤활이론과 이 를 스푸울 밸브의 그루브 설계에 적용하는 방법을 소 
개하였다. 유압장치는 소형으로 대출력이 가능하기 때문에 널리 사용되며, 이를 위해서는 고압이 우선적 으로 요구된다. 특히, 적용되는 유압부품은 하중의 작 용방향과 운전속도가 변하는 경우가 대부분이다. 또 한, 유압유의 유동과 점성마찰 등에 의한 에너지 손 실이 유압유의 온도상승과 이로 인한 점도저하, 부품 의 열변형/탄성변형 등을 초래한다. 따라서, 고성능과 고신뢰성인 유압부품의 생산에 요구되는 구성부품의 윤활성능예측이 본 해설이 조금이라도 도움이 되기를 희망한다.

\section{참고 문헌}

1) Dowson, D., History of Tribology, Professional Engineering Publishing, 1998.

2) Reynolds, O., "On the Theory of Lubrication and Its Application to Mr. Beauchamp Tower's Experiments, Including an Experimental Determination of the Viscosity of Olive Oil", Philos. Trans. R. Soc. London, Vol.177, pp. 157-234, 1886.

3) Hamrock, B., Fundamentals of Fluid Film Lubrication, McGraw-Hill, 1994.

4) Meritt, H. E., Hydraulic Control Systems, John Wiley \& Sons, 1967.

5) Sweeney, D. C., "Preliminary Investigation of Hydraulic Lock", Engineering, Vol.172, pp.513-516, 1951.

6) Manhajm, J. and Sweeney, D. C., "An Investigation of Hydraulic Lock", Proc. of Instn. Mech. Engrs., Vol.169, pp.865-879, 1955.

7) Mannam, J., "Further Aspects of Hydraulic Lock", Proc. of Instn. Mech. Engrs., Vol.173, pp.699-716, 1959.

8) Sweeney, D. C.,, "Eight Ways to Overcome Hydraulic Lock", Engineering, Vol.190, pp.592-593, 1960.

9) Kettleborough, C. F., "The Effect of Pressure on Viscosity in Hydraulic Lock", Int. J. Mech. Sci., Vol.3, pp.137-142. 1961.

10) Hessey, M. F., Martin, B. P. and Brighton, D. K., "Hydraulic Lock Forces on Tapered Pistons", Proc. Instn. Mech. Engrs., Vol.184, pp.983-992, 1969-1970.
11) Etsion, I. and Pinkus, O., "The Hydrodynamics of a Plug Bearing", Trans. ASME, J. of Lub. Tech., Vol.98, pp.433-440, 1976.

12) Meikandan, N., Raman, R., Singaperumal, M. and Seetharamu, K. N., "Theoretical Analysis of Tapered Pistons in High Speed Hydraulic Actuators", Wear, Vol.137, pp.299-321, 1990.

13) Lee, C. O. und Park, T. J., "Querkräfte an hydraulischen Ventilen mit mehreren Umfangsnuten", Ölhydraulik und Pneumatik, Vol.34, pp.269-274, 1990.

14) 박태조, 이정오, "그루브를 한 유압 피스톤펌프의 피스톤에 작용하는 측력의 해석", 한국윤활학회 지, Vol.8, No.8, pp.44-49, 1992.

15) Sasaki, A. and Yamamoto, T., "Review of Studies of Hydraulic Lock", Lubrication Engineering, Vol.49, pp.585-593, 1993.

16) Park, T. J. and Lee, C. O., "Hydrodynamic Lateral Force on a Tapered Piston Subjected to a Large Pressure Gradient", Proc. of 3rd ICFP, pp.44-48, 1993.

17) 이정오, 박태조, 피스톤 형상이 유압피스톤 펌프. 모터의 윤활특성에 미치는 영향, 한국윤활학회지, Vol.10, No.3, pp.47-53, 1994.

18) Borghi, M., Cantore, G., Milani, M. and Paoluzzi, R., "Numerical Analysis of the Lateral Forces Acting on Spools of Hydraulic Components", Proc. of ASME, Int. Mech. Eng. Congress and Expo., Vol.5, pp.149-156, 1998.

19) Milani, M., "Designing Hydraulic Locking Balancing Grooves", Proc. of Instn. Mech. Engrs., J. of Systems and Control Eng., Vol.215, pp.453-465, 2001.

20) Belforte, G., Raparelli, T., Mazza, L. and Trivella, A., "Analysis, Design, and Comparison of Different Types of Pistons for Sealless Pneumatic Cylinders and Valves", Tribology Trans., Vol.48, No.3, pp.377-388, 2005.

21) Borghi, M., "Hydraulic Locking-in Spool- Type Valves : Tapered Clearances Analysis", Proc. of Instn. Mech. Engrs., J. of Systems and Control Eng., Vol.215, pp.157-168, 2001.

22) 박태조, "압력에 따른 점도변화가 그루브를 한 유 압 스푸울 밸브에 미치는 영향", 한국윤활학회지, 
Vol.22, No.6, pp.307-313, 2006.

23) FLUENT, FLUENT 6.0 Manual, 2002.

24) Moffatt, H. K., "Viscous and Resistive Eddies near a Sharp Corner", J. Fluid Mech., Vol.18, pp.1-18, 1964.

25) Cheng, M. and Hung, K. C., "Vortex Structure of Steady Flow in a Rectangular Cavity", Computers and Fluids, Vol.35, No.10, pp.1046-1062, 2006.

26) Brizmer, V., Kligerman, Y. and Etsion, I., "A Laser Surface Textured Parallel Thrust Bearing", Tribology Trans., Vol.46, pp.397-403, 2003.

27) Etsion, I., "State of the Art in Laser Surface Texturing", J. of Tribology, Vol.127, pp.248-253, 2005.

28) Feldman, Y., Kligerman, Y., Etsion, I. and Haber, S., "The Validity of the Reynolds Equation in Modeling Hydrostatic Effects in Gas Lubricated Textured Parallel Surfaces," J. of Tribology, Vol. 128, pp. 250-345, 2006.

29) 박태조, 황윤건, "Laser Texturing한 평행 스러스 트 베어링의 윤활특성 : 제 1 보 - 딤플 깊이의 영 향", 한국 윤활학회지, Vol.25, No.5, pp305-310, 2009.
30) 박태조, 황윤건, "Laser Texturing한 평행 스러스 트 베어링의 윤활특성 : 제2보 - 딤플 위치의 영 향", 한국윤활학회지, Vol.26, No.1, pp.1-6, 2010.

31) 박태조, "Laser Texturing한 평행 스러스트 베어 링의 윤활특성 : 제 3 보 - 딤플 수의 영향", 한국 윤활학회지, Vol.27, No.6, pp.302-307, 2011.

32) 박태조, "Laser Texturing한 평행 스러스트 베어 링의 윤활특성 : 제 4 보 - 딤플 형상의 영향", 한 국윤활학회지, Vol.27, No.6, pp.338-343, 2011.

33) 이준오, 박태조, "표면조직 가공한 유압부품면에 서의 윤활특성", 유공압건설기계학회 논문집, Vol.9, No.4, pp.26-31, 2012.

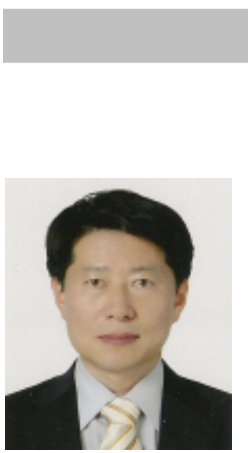

[저자 소개]

\section{박태조}

E-mail : tjpark@gnu.ac.kr

Tel : 055-772-1623

1990년 KAIST 기계공학과 박사. 1991 년 현재 경상대학교 기계공학부 교수 구름베어링, 유압부품, 냉동공조용 압축 기부품의 윤활해석, Seal 설계, Coating 부품의 접촉해석 등 기계부품의 Tribology 분야를 주로 연 구. 유공압건설기계학회, 한국윤활학회, 대한기계학회, 한국정 밀공학회, 한국자동차공학회 등의 회원, 공학박사 